\title{
The Importance of Good Working Relationships between Principals and School Board Members in Zambezi Region, Namibia
}

\author{
Stanley C. Chombo \\ Department of Education in Languages, Humanities and Commerce, Faculty of Education, University of Namibia, Katima Mulilo \\ Campus, Katima Mulilo, Namibia \\ Email: schombo@unam.na
}

How to cite this paper: Chombo, S. C. (2020). The Importance of Good Working Relationships between Principals and School Board Members in Zambezi Region, Namibia. Creative Education, 11, 1666-1678. https://doi.org/10.4236/ce.2020.119121

Received: July 17, 2020

Accepted: September 12, 2020

Published: September 15, 2020

Copyright $\odot 2020$ by author(s) and Scientific Research Publishing Inc. This work is licensed under the Creative Commons Attribution International License (CC BY 4.0).

http://creativecommons.org/licenses/by/4.0/ (c) (i) Open Access

\begin{abstract}
The purpose of this study was to establish the importance of a good working relationship between principals and school board members (SBMs) in Zambezi region. The study adopted a qualitative research design approach. The data was gathered using interviews. In this study, the researchers worked with principals and SBMs in Zambezi region, Namibia. For the purpose of the study, the researcher selected five principals, nine teacher SBMs, ten parent SBMs and four learners' representative council members (LRCs) from primary, combined and senior secondary schools in the Zambezi region. The reason for selecting the twenty-eight participants was their involvement as members of school boards in the Zambezi region. A qualitative data analysis (QDA) was employed in this study. The findings derived from principals' comments revealed that, when there was a good working relationship between principals and SBMs, it became easier to maintain discipline among learners at the school. Good performance and good academic results of learners could be achieved at the school. The majority of principals and teacher SBMs seemed to be working together in ensuring that the school achieved the targeted goals and objectives. Principals and SBMs are important partners when it comes to the smooth running of the school. It was revealed from the findings derived from the comments of principals that the importance of a good working relationship with SBMs was the development of unity and trust. It was revealed from the findings derived from the comments of principals, parent SBMs and LRCs serving on the school board that the importance of a good working relationship also related to consultations on matters regarding school development. From the findings of this paper, the researcher can confirm that, to work properly, principals and SBMs should have a healthy working relationship.
\end{abstract}




\section{Keywords}

School Board Members, Principals, Relationship, Parents, Teachers, Learners' Representative Council (LRCs) Members

\section{Introduction}

Fullan (2012: p. 1) posits that building relationships is one of the components of leadership. Other components that Fullan (2012: p. 1) identifies include focusing on a small number of ambitious goals or priorities, persistence, developing capacity and spreading quality implementation. Sallee (2014: p. 25) states that relationships are vital factors in schools. The principal should make relationship building a priority for meaningful results in the school. When considering this, principals must understand the importance of placing a high value on people and relationships. However, it is argued that the best principal spends an intense amount of time on developing, improving and investing in relationships. This is supported by Spicer (2016: p. 29) who states that strong relationships in the school are afforded when the principal accepts, respects and exalts employees. This study validates Sallee's (2014: p. 25) statement that positive relationships are at the heart of what makes a school extraordinary. Equally important is that relationships must be professionally supportive, sincere and consciously developed. Spicer (2016: p. 10) acknowledges that principals, who can build relationships with SBMs and interact with them, hold the central elements for creating a positive school climate. In order to create a positive school climate, principals must be consummate relationship builders within groups, especially with SBMs. When principals lead by example and work to build trust, shared values and a shared vision, working relationships improve and SBMs are happier with their jobs.

\section{Research Objective}

To establish the importance of a good working relationship between principals and SBMs in the Zambezi region.

\section{Literature Review}

\section{Elements Needed to Build Relationships}

The first key element needed to build a relationship is building trust. Ament (2013: p. 64) explains that taking time to build trust is imperative for SBMs to adapt the mission, vision and core beliefs of the school in order for learners to learn at a high standard and with clear expectations. It is, however, important to note that trust is something that the principal must maintain with the SBMs. Equally, trust is earned and not gained automatically by virtue of the position. Building trust is the first step to bring the team together to work as one unit in order to open the opportunities for informal network collaboration and colla- 
borative innovation. Whitehead, Boschee and Decker (2013) reiterate that, when teachers and principals are cooperative and trust efforts are strong, learners experience greater academic challenges and a greater sense of well-being.

The second key element is effective communication. Ament (2013: p. 52) affirms that effective communication is a critical component in the development of trust. This is supported by Ehren, Honingh, Hooge and O'Hara (2016: p. 212) who acknowledge that SBMs should establish a strong communication structure to inform and engage both internal and external stakeholders in setting and achieving school goals. SBMs should receive information from various sources, for example, principals, teachers and outside sources. They should share the information received among all SBMs and communicate actions and goals to staff members. Bauer and Brazer (2012: p. 46) affirm that communication is critical to involving others, both from the school and apart from it. It is, therefore, important to note that communication does not need to be sophisticated or lengthy, but it does need to be regular. This is acknowledged by Steyn and Van Niekerk (2012: p. 143) who emphasize that effective communication needs to be simple, but is an amazingly powerful tool that gives principals an edge and allows them to win the war of words every time. Thus, principals must employ suitable words and nonverbal signs (smiling, tone of voice, eye contact) which fit into the receiver's frame of reference in order for communication to be effective.

The third key element needed to build relationship is encouraging constructive conflict around ideas. Van der Westhuizen (2015: p. 308) states that conflict in the sense of an honest difference of opinion, where a choice must be made between two alternative methods, is unavoidable and can be a valuable exercise. Constructive conflict ensures that all the possibilities are carefully considered and that future planning is done, based on the advantages and disadvantages which the alternatives offer. Boucher (2013: p. 67) reiterates that principals consider constructive conflict around ideas as an important skill that contributes to a positive school climate.

\section{Methodology}

\subsection{Research Design}

A qualitative research design approach was employed using interviews to establish the importance of a good working relationship between principals and SBMs in the Zambezi region. The interviews in this study were employed to help establish the experiences of principals and SBMs (Ary, Jacobs, Sorensen, \& Walker, 2014: p. 466-467), and they provided the required information.

\subsection{Sample of the Study}

The sample in this study included five principals, nine teacher SBMs, ten parent SBMs and four LRCs from primary, combined and senior secondary schools in the Zambezi region. The reason for selecting the twenty-eight participants was their involvement as members of school boards in the Zambezi region. 


\subsection{Data Analysis}

A qualitative data analysis (QDA) was employed in this study to analyze the data based on an "interpretative philosophy that is aimed at examining meaningful and symbolic content of meaning of a specific phenomenon by analyzing their perceptions, attitudes, understanding, knowledge, values, feelings and experiences in an attempt to approximate their construction of the phenomenon" (Maree, 2016: p. 109). QDA was the method best suited to establish the importance of a good working relationship between principals and SBMs in the Zambezi region. The researcher analyzed transcripts of interviews that were conducted with five principals and twenty-three SBMs, a total of twenty eight participants.

\section{Findings}

In this section, the researcher presents the findings derived from the comments of principals and SBMs regarding the importance of a good working relationship.

\subsection{Importance of a Good Working Relationship with Parent SBMs as Perceived by Principals}

Participating principals in this study outlined some importance of good working relationships with parent SBMs. Below are the categories and findings that emerged from their responses.

Category 1: Easy to maintain discipline among learners

Jerome, principal of School One, stated that when there was a good working relationship with the parent SBMs at the school, it was easy to maintain discipline among learners. This, according to him, entailed that a well-disciplined child at home would not give headaches or problems when he came to school. He stressed that the same applied to a religious child who was brought up by religious parents. Therefore, if one had such a good working relationship with parent SBMs, it would be very easy to maintain discipline among learners because parents at home would embody what was taught at school.

Category 2: Achievement of targeted goals and objectives

Michael, principal of School Three, pointed out that the importance of good working relationship with parent SBMs was that the school would achieve its targeted goals and objectives. He stated that every year they normally planned together with parent SBMs at their school. In the action plan for the school, certain goals and objectives were set. For example, he said:

The plan of action indicates that at least $90 \%$ of our learners must be promoted to the next Grade. All these steps are followed and at the end of the year, we review what we have achieved. We sit together with parent school board and review our goals and objectives to see if the majority of the things we set for ourselves have been achieved.

Michael stressed that a good working relationship with parent SBMs would 
enhance the good results of learners at the school.

Category 3: Parent SBMs have trust in the school authorities

Postrick, principal of School Four, noted that sometimes parent SBMs felt as if the principal did not acknowledge them as SBMs. During school board meetings, they did not speak out their ideas as there was not much trust. He stated that, if parent SBMs were given the opportunity to share their ideas during school board meetings, they would feel recognized and trusted by the school authority, specifically by the principal. He stated as follows:

They will even say that my idea can be listened to by the principal. Parents sometimes will feel that I did not go far with education; I am just a taxi driver. When I raised my idea, the principal agreed. So they will feel valuable and useful. They will feel that they are part of the school. Parents will have trust in the principal.

Category 4: Consultation and school development

Shane, principal of School Five, who stated that parent SBMs could consult the principal freely on matters regarding the development of the school, mentioned this importance. He said:

Equally, if there is no good working relationship between me and parent $S B M s$, there is no way we are going to drive the school in the right direction. We shall not feel free to consult each other. The moment we stop consulting each other the school will not develop and that will eventually affect the learners.

Category 5: Smooth running of the school

Linus, principal of School Six, asserted that the main aim of having parent SBMs was to oversee the smooth running of the school. This could be realized if the principal and parent SBMs were working together. He stated that the moment the principal and parent SBMs worked on their own, there would be no development taking place at the school. He then stressed that it was important that all SBMs worked as a team for the smooth running and proper functioning of the school for the benefit of the learners.

\subsection{Importance of a Good Working Relationship with Teacher SBMs as Perceived by Principals}

When principals were asked a similar question during the interviews regarding the importance of a good working relationships with teacher SBMs, most of them reiterated the importance, which they mentioned on parent SBMs and added a few. The following categories and findings were revealed:

Category 1: Consultation and school development

Shane, principal of School Five who stated that teacher SBMs could consult the principal freely on matters regarding the development of the school, mentioned this importance.

Category 2: Smooth running of the school

Linus, principal of School Six, asserted that the main aim of having teacher SBMs was to oversee the smooth running of the school. This could be realized if 
the principal and teacher SBMs were working together. He stated that the moment the principal and teacher SBMs worked on their own, there would be no development at the school. He then stressed that it was important that all the stakeholders on the school board worked as a team for the smooth running and proper functioning of the school for the benefit of the learners.

Category 3: Easy to maintain discipline among learners

Jerome, principal of School One, stated that when there was a good working relationship with the teacher SBMs at the school, it would be easy to maintain discipline among learners at the school. He stated that teachers were handling the core activity of teaching and learning. He said:

It is paramount to make sure that my working relationship with stakeholders such as teacher SBMs is mutual.

Category 4: Conducive working environment

Regarding this, Jerome stated that it was his role to cultivate a conducive working environment for teachers at the school. He said that:

Teachers need to feel safe, happy as well as to feel home for them to be able to do their job. Therefore a good relationship with them will promote better results for the school and for the children.

Category 5: Foster unity and trust

Postrick, principal of School Four, affirmed that the importance of a good working relationship with teacher SBMs at the school was to foster unity with teachers. He said:

Even if there is a bitter argument among us, whereby it is difficult to convince teacher SBMs, as a principal I have to compromise and find a way to resolve the argument. The benefit is that teacher SBMs will learn to trust the principal.

\subsection{Importance of a Good Working Relationship with LRCs Serving on the School Board as Perceived by Principals}

When principals were asked during the interviews about the importance of a good working relationships with LRCs on the school board, some of them echoed the importance which they cited with teacher SBMs, and added a few.

The following categories and findings were reiterated:

Category 1: Consultation and school development

Shane, principal of School Five, who stressed that LRCs on the school board could consult the principal freely on matters regarding the school development, mentioned this importance.

Category 2: Smooth running of the school

Linus, principal of School Six, emphasized that the main aim of LRCs serving on the school boards was to oversee the smooth running of the school. This could be realized if the principal and LRCs serving on the school boards were working together to ensure that quality teaching and learning were taking place at the school.

Category 3: Enhancing good academic results for learners at the school 
Michael, principal of School Three, asserted that a good working relationship with LRCs serving on the school board could encourage good academic results for learners at the school. He stressed that, to achieve good results, the principal and LRCs had to work as a team and pull in one direction.

Category 4: Building trust

Postrick, principal of School Four, revealed this during the interview. He stated that, if LRCs serving on the school board had trust in the principal, they would not fear him, as they would express their ideas freely. He said:

Sometimes even when a learner speaks during the school board meeting, I can amplify what the learner is saying. After the meetings, you can see that these learners are getting used to you.

\subsection{Importance of a Good Working Relationship with Principals as Perceived by Parent SBMs}

In this section, the researcher presents the findings derived from the comments of parent SBMs regarding the importance of a good working relationship with principals. The following categories and findings were reiterated:

Category 1: School development

Parent SBMs who participated in the study were asked about the importance of a good working relationship with the principals. They responded differently to the question. This was evident from the response of Francis, a parent SBM at School One, who cited the importance. He stated that the importance of a good working relationship with the principal was that there would be development taking place at the school. He said:

Without a good working relationship, there will be no developments at the school and learners will end up failing.

Francis pointed out that learners could fail if the working relationship between the principal and parent SBMs was not collegial. Jimmy, a parent SBM at School Three stated that it was good to have a good working relationship with the principal and that, if the working relationship with the principal was not good, learners would fail. He stressed that:

Learners always inform their parents regarding the teachers who are not teaching at school. As parent SBMs normally, we advise the principal to take appropriate measures against such teacher.

Category 2: Good communication

Jinny, a parent SBM at School Four cited two importance aspects of a good working relationship with the principal. The first was that both principals and parent SBMs would be able to communicate freely.

Category 3: Enhancing good working relationship

Secondly, Jinny, a parent SBM at School Four, said that it enhanced a good working relationship among SBMs and learners. Collins, a parent SBM at School Two, noted that the importance of a good working relationship with the principal was to help solve problems at the school. The principal could call the parent SBMs at any time to solve that problem. He stated that when there was the 
problem of a shortage of chairs and desks at their school, the principal and parent SBMs were involved in finding a solution. Grace, a parent SBM at School One, stated that the importance of a good working relationship with the principal was that they would be able to work together. Ricky, a parent SBM at School Three, stressed that, since they had a good working relationship with the principal, they were able to address the issue of corporal punishment at the school.

Category 4: Conducive learning atmosphere

Jinny, a parent SBM at School Four, stated that a good working relationship with the principal would create a conducive learning atmosphere at the school. He noted that the process of teaching and learning would be smoothened.

Lucious, a parent SBM at School Five, affirmed that the importance of a good working relationship with the principal was that:

The results for learners at the school will be good at the end of the year because this is what parents are interested to see.

\subsection{Importance of a Good Working Relationship with the Principal as Perceived by Teacher SBMs}

Teacher SBMs were also asked a similar question as parent SBMs during the interviews, namely what was the importance of a good working relationship with the principals? The following categories and findings were reiterated:

Category 1: Smooth running of the school

Some of the teacher SBMs participants in this study pointed out that the importance of a good working relationship with the principal was the smooth running of the school. This could be seen from their responses below:

For the school to run smoothly the principal must be in touch with the teacher SBMs. All that he needs to do is to have full participation of all SBMs. For example, when it comes to the appointment of teachers and for any development to take place at the school, the SBMs must be there to assist him. One person cannot develop the school; many people can develop the school. If the principal want to develop the school alone, he will certainly fail (Linus, teacher SBM at School Four).

Having a good working relationship with the principal helps with the smooth running of the school. Without a good working relationship, the school will not drive forward. The principal at the school is the one who give instructions and subordinates must carry out those instructions. So if they is a poor working relationship between the teachers and the principal, the principal will fail to run the school and as teachers we will also fail in our duties leading to learners at the school to also fail at the end of the year (James, teacher SBM at School Five).

Category 2: Achievement of school goals and objectives

The other importance of good working relationships with the principal that was cited by teacher SBMs during the interviews was that the goals and objectives of the school would be achieved. Some teacher SBMs participants affirmed that, when the goals and objectives of the school were set, everyone would work towards those goals and objectives. They stated that everyone would own the 
goals and objectives set and work hard to achieve them. Everyone would strive to work very hard at the school. This would only be possible when there was a mutual working relationship with the principal at the school.

Category 3: Transparency

Fidel, teacher SBM and HOD at School Four, revealed that the importance of a good working relationship with the principal was that there would be transparency of whatever was done at the school. He stated that if the working relationship with the principal were good, things would move at the school. He said:

We are going to work as a team to solve issues at the school.

Without substantiating much on the same point Maggy, teacher SBM at School One, stated that the importance of good working relationships with the principal was that there would be transparency at the school. She said:

There is nothing that the principal will do alone. He will always invite us and inform us.

Category 4: Conducive working environment

Nina, a teacher SBM at School Six, asserted that:

The good thing regarding having a good working relationship with the principal is that our working environment will be good. At the same time, it will improve the learners' results. If the teacher is happy he/she can work very hard but if the working relationship with the principal is not good, there is no way that teacher can produce good results.

Category 5: Enhancing good academic results for learners at the school

Ben, a teacher SBM at School Three, emphasized that:

If you oppose each other, you are not going to progress and the academic results of the school will be very poor. If you work together the school board and the principal you will achieve good academic results for learners.

In addition, Rose, a teacher SBM and HOD at School Two, noted that the importance of a good working relationship with the principal was that it would improve learners' achievement at the school. She said that this could be attained if the principal and teacher SBMs worked as a team.

\subsection{Importance of a Good Working Relationship with the Principal as Perceived by LRCs Serving on the School Board}

Similar to teacher SBMs, LRCs serving on the school board were asked during the interviews about the importance of a good working relationship with the principals. The following categories and findings were revealed:

Category 1: Good communication

Some LRCs serving on the school board stated that a good working relationship with the principal was important to enhance good communication at the school. This, according to some LRCs, will lead to a healthy working relationship with the principal.

Category 2: Learners' satisfaction

Diana, LRC for culture at School Five, affirmed that a good working relationship with the principal would lead to satisfied learners at the school. She reite- 
rated that:

I will take you back on the issue of the school uniform. If we had a good working relationship with the principal, if the principal was someone who is willing to listen to us as LRCs, the whole complication on the issue of the new school uniform would not be there.

Category 3: School development

In addition, Evans, president of the LRCs at School Five asserted that a good working relationship with the principal was something good. He said:

It can build the school. It can help us to develop the school because we will not be having opposing ideas.

\subsection{Summary on the Importance of a Good Working Relationship between Principals and SBMs}

This section presented the findings regarding the importance of a good working relationship between principals and SBMs. The following Table 1 indicates the categories that emerged from their responses.

Table 1. Importance of a good working relationship between principals and SBMs.

\begin{tabular}{|c|c|c|c|c|}
\hline Categories & Principals & $\begin{array}{l}\text { Parent } \\
\text { SBMs }\end{array}$ & $\begin{array}{l}\text { Teacher } \\
\text { SBMs }\end{array}$ & $\begin{array}{l}\text { LRCs serving } \\
\text { on the SB }\end{array}$ \\
\hline $\begin{array}{l}\text { 1) Easy to maintain discipline among } \\
\text { learners }\end{array}$ & $\sqrt{ }$ & & & \\
\hline $\begin{array}{l}\text { 2) Achievement of targeted goals and } \\
\text { objectives }\end{array}$ & $\sqrt{ }$ & & $\sqrt{ }$ & \\
\hline $\begin{array}{l}\text { 3) Parent SBMs felt recognized and had trust } \\
\text { in the school authorities }\end{array}$ & $\sqrt{ }$ & & & \\
\hline 4) Consultation and school development & $\sqrt{ }$ & $\sqrt{ }$ & & $\sqrt{ }$ \\
\hline 5) Smooth running of the school & $\sqrt{ }$ & & $\sqrt{ }$ & \\
\hline 6) Conducive working environment & $\sqrt{ }$ & $\sqrt{ }$ & $\sqrt{ }$ & \\
\hline 7) Foster unity and trust & $\sqrt{ }$ & & & \\
\hline $\begin{array}{l}\text { 8) Enhances good academic results for } \\
\text { learners at the school }\end{array}$ & $\sqrt{ }$ & & $\sqrt{ }$ & \\
\hline 9) Good communication & & $\sqrt{ }$ & & $\sqrt{ }$ \\
\hline 10) Enhances good working relationship & & $\sqrt{ }$ & & \\
\hline 11) Transparency & & & $\sqrt{ }$ & \\
\hline 12) Learners' satisfaction & & & & $\sqrt{ }$ \\
\hline 13) School development & $\sqrt{ }$ & $\sqrt{ }$ & & $\sqrt{ }$ \\
\hline
\end{tabular}

\section{Discussion of Findings}

In this section, the researcher discusses the findings regarding the importance of a good working relationship between principals and SBMs in the Zambezi region, Namibia. 
The findings from interviews revealed that the importance of a good working relationship between principals and SBMs was that unity and trust were developed. Participating principals noted that sometimes parent SBMs felt that the principal did not acknowledge them as SBMs. During school board meetings, they did not offer their ideas, as there was not much trust. They stated that, if parent SBMs were given the opportunity to share their ideas during school board meetings, they would feel recognized and trusted by the school authority, specifically the principal. The finding is in agreement with Ament (2013: p. 64), namely that taking time to build trust is imperative for SBMs to adapt the mission, vision and core beliefs of the school in order for learners to progress with high standards and clear expectations. It is important to note that trust is something that the principal must maintain with the school board members. Spicer (2016: p. 10) acknowledges that principals who can build relationships with SBMs and interact with them, hold the central elements for creating a positive school climate. In order to create a positive school climate, principals must be consummate relationship builders in groups, especially with SBMs. When principals lead by example and work to build trust, shared values and a shared vision and working relationships improve and SBMs are happier with their jobs.

The importance of a good working relationship between principals and SBMs cited by participants in this study revealed that they understood and adhered to what was stated in the policy documents of the Ministry of Education, Arts and Culture (2016: p. 5-13). The findings from interviews revealed that the majority of participating principals, parents and teacher SBMs affirmed that, when there was a good working relationship between principals and SBMs at the school, it became easier to maintain discipline among learners. Participating principals and SBMs seemed to be working together in maintaining discipline at the school. This importance is similar to the role, responsibilities of SBMs as outlined by the Ministry of Basic Education, Sport and Culture (2001: p. 6) that principals and SBMs should be able to exercise discipline at the school.

The findings from interviews revealed that principals and SBMs were important partners when it came to the smooth running of the school. Participating principals and some SBMs emphasized that the importance of a good working relationship between the two stakeholders in education was to oversee the smooth running of the school. This can be realized when the principal and SBMs are working together to ensure that quality teaching and learning are taking place at the school. The finding is in line with observations made by Onderi and Makori (2012: p. 27), namely that the role of SBMs is to facilitate the smooth operation of teaching and learning in schools through the provision of teaching and learning materials. Similar observations are made by the Ministry of Education, Arts and Culture (2016: p. 29), namely that the principal is morally and legally obliged to cooperate with the school board in the best interest of the school.

The findings from interviews revealed that there were consultations between principals and SBMs on matters regarding school development. Participating 
principals during interviews affirmed that, without a good working relationship with SBMs, there was no development at the school and learners ended up failing. The findings are in line with what is stated in the GM South Africa Foundation (Department of Education, 2012: p. 9-11) that a school board is responsible for deciding the framework for the conduct and development of the school. This is also in line with the roles and responsibilities of SBMs as stated by the Ministry of Basic Education, Sport and Culture (2001: p. 15), namely that a school board needs to work together with the community to help the development of the school's infrastructure. The school board can organize community members to carry out building projects, such as building a school library and a school hall.

\section{Conclusion}

The purpose of this study was to establish the importance of a good working relationship between principals and SBMs in Zambezi region, Namibia. From the findings of this study, the researcher can confirm that, to work properly, principals and SBMs should have a healthy working relationship. To maintain a good working relationship, unity and trust, understanding of and adherence to policy, consultations and communication among SBMs are vital, not only in Namibia but world-wide.

\section{Conflicts of Interest}

The author declares no conflicts of interest regarding the publication of this paper.

\section{References}

Ament, T. H. (2013). The Role of the Superintendent and School Board Chair in Building Relational Trust with Newly Elected Board Members in Small Rural Washington School Districts. Pullman: Washington State University.

Ary, D., Jacobs, L. C., Sorensen, C. K., \& Walker, D. A. (2014). Introduction to Research in Education (9th ed.). Wadsworth, OH: Cengage Learning.

Bauer, C. B., \& Brazer, S. D. (2012). Using Research to Lead School Improvement. Turning Evidence into Action. Thousand Oaks, CA: SAGE Publications, Inc.

Boucher, M. M. (2013). The Relationship of Principal Conflict Management Style and School Climate. Doctoral Dissertation. http://scholarcommons.sc.edu/etd/948

Department of Education (2012). GM South Africa Foundation, Introduction to School Governance: School Governing Body Induction/Training Manual. Province of the Eastern Cape Education.

Ehren, M. C. M., Honingh, M. E., Hooge E. H., \& O’Hara, J. (2016). Changing School Board Governance in Primary Education through School Inspections. Educational Management Administration \& Leadership, 44, 205-223. https://doi.org/10.1177/1741143214549969

Fullan, M. (2012). What America Can Learn from Ontario's Education Success. http://www.michaelfullan.ca/media/13462760640.pdf

Maree, K. (2016). First Steps in Research (2nd ed.). Braamfontein: Van Schaik Publishers.

Ministry of Basic Education, Sport and Culture (2001). Education Act, 2001(Act No 16 of 
2001) and Regulations Made under the Education Act. Windhoek.

Ministry of Education, Arts and Culture (2016). Establishing and Maintaining Effective School Boards. A Guide. Windhoek.

Onderi, H., \& Makori, A. (2012). Differential Perceptions, Challenges, Conflicts and Tensions in the Role of Board of Governors (BOG) and Parents-Teacher Association (PTA) in Sub-Saharan Africa: A Case of Kenyan Secondary Schools. Educational Research, 3, 17-29.

Sallee, A. M. (2014). Building Meaningful Relationships and Enhancing Teacher Efficacy: A Study of the Quality of the Leader Follower Relationship and Its Impact on Teacher Efficacy. Chattanooga, TN: The University of Tennessee.

Spicer, F. V. (2016). School Culture, School Climate, and the Role of the Principal. Dissertation, Atlanta, GA: Georgia State University.

http://scholarworks.gsu.edu/eps-diss/140

Steyn, G. M., \& Van Niekerk, E. J. (2012). Human Resources Management in Education (3rd ed.). Braamfontein: Unisa Press.

Van der Westhuizen, P. C. (2015). Effective Educational Management. Cape Town: Kagiso Tertiary.

Whitehead, B. M., Boschee, F., \& Decker, R. H. (2013). The Principal: Leadership for a Global Society. Thousand Oaks, CA: SAGE Publications, Inc.

https://doi.org/10.4135/9781544308609 